IZA DP No. 8113

Are All of the Good Men Fathers?

The Effect of Having Children on Earnings

Astrid Kunze

April 2014 


\title{
Are All of the Good Men Fathers? The Effect of Having Children on Earnings
}

\author{
Astrid Kunze \\ NHH Norwegian School of Economics \\ and IZA
}

Discussion Paper No. 8113

April 2014

IZA

P.O. Box 7240

53072 Bonn

Germany

Phone: +49-228-3894-0

Fax: +49-228-3894-180

E-mail: iza@iza.org

Any opinions expressed here are those of the author(s) and not those of IZA. Research published in this series may include views on policy, but the institute itself takes no institutional policy positions. The IZA research network is committed to the IZA Guiding Principles of Research Integrity.

The Institute for the Study of Labor (IZA) in Bonn is a local and virtual international research center and a place of communication between science, politics and business. IZA is an independent nonprofit organization supported by Deutsche Post Foundation. The center is associated with the University of Bonn and offers a stimulating research environment through its international network, workshops and conferences, data service, project support, research visits and doctoral program. IZA engages in (i) original and internationally competitive research in all fields of labor economics, (ii) development of policy concepts, and (iii) dissemination of research results and concepts to the interested public.

IZA Discussion Papers often represent preliminary work and are circulated to encourage discussion. Citation of such a paper should account for its provisional character. A revised version may be available directly from the author. 


\section{ABSTRACT}

\section{Are All of the Good Men Fathers? The Effect of Having Children on Earnings ${ }^{*}$}

This study reconsiders the empirical question of whether men's earnings increase because of children. Large Norwegian register data are used for brother and twin pairs who are followed over their life cycle from their first entry into the labour market. The data permit family-fixed effects to be modeled in various ways, as well as observing earnings growth before and after having children. The simple conditional correlation between children and earnings is positive. When only variation from between-sibling differences is used, the earnings effect post entry into first-fatherhood declines. The effect becomes small and non-significant when we use twins.

JEL Classification: J220, J240, J310, J130, J160

Keywords: children, earnings, men, siblings, twins

Corresponding author:

Astrid Kunze

NHH Norwegian School of Economics

Helleveien 30

5045 Bergen

Norway

E-mail: Astrid.Kunze@nhh.no

\footnotetext{
* For comments on previous versions of the paper I would like to thank Shelly Lundberg, Oddbjørn Raaum, Bernt Bratsberg, Simen Markussen, Kjell Salvanes, FrankWindmeijer, Mette Ejrnæs, Michael Burda, Ken Troske, John Ermisch, Arnaud Chevalier and Amalia Miller for their comments, as well as participants at seminars at the ELE Workshop on Family Economics, $\mathrm{NHH}$, University of Bergen, University of Freiburg, University of Mannheim, ISER (Essex), ESOP (Oslo), SOLE (Chicago), RAND (Washington D.C.), University of Copenhagen, Frisch Center, University of Aarhus, RWI Essen, University of Hamburg, University of Cologne and ZEW.
} 


\section{Introduction}

Women traditionally take greater responsibility for rearing children, with many articles having shown that women's earnings drop when they have children. Part of this drop captures decreased labour supply post childbirth, through periods of leave or reduced hours of work, as well as the depreciation of human capital during leave periods. The unexplained drop that studies in this literature find even after controlling for many productivity-related factors is consistent with several explanations; for example, compensating wage differentials if mothers trade more family friendly working conditions for wages after childbirth. ${ }^{1}$ Evidence on men's earnings and children is scarce, and the general finding is that men's earnings increase after having children. This seems a paradox in light of the standard economic explanations applied in the literature on women. Traditionally, fathers do not adjust their labour supply to care for their children ${ }^{2}$ and therefore we would not expect an effect of children. Hence, this finding questions either standard economic explanations or previous empirical findings.

This study contributes new empirical evidence concerning the effect of children on men's earnings, using register data on Norway on large samples of brothers and twins who are followed over most of their life cycle. We estimate flexible log earnings regressions where the unobserved heterogeneity component is common to brothers. The main result is that when we use variation from the comparison of men's earnings to their twin brothers, the effect of children is not significantly different from zero; the point estimate is +2 per cent per year. This is the mean effect post entry into first fatherhood.

\footnotetext{
${ }^{1}$ Other explanations are reduced work effort (Becker, 1985) and employer discrimination. For empirical studies, see e.g. Bertrand, et al. 2010, Waldfogel (1998), Joshi et al. (1999), and Anderson, et al. (2002), Gupta and Smith (2002).

${ }^{2}$ Although this statement is (still) true, the Nordic countries are exceptions, having introduced a paternity leave quota, Norway in 1993, that has led to some fathers taking 1-4 months of leave during the first year after the birth of the child. Nonetheless, virtually all fathers work full-time.
} 
It is important to understand the costs and gains from having children because they are directly related to the demand for children, as well as the design of policies. Examples are divorce settlements and pension schemes that compensate mothers for time out of work due to caring for their own children. Costs through labour adjustments related to children are understood as an important contributor to the gender wage gap ${ }^{3}$, which policy makers try to diminish. Fathers have also attracted increasing interest in this debate, because we can observe from the data that men have increased their weight on family values (see e.g. Goldin 2006), as well as their involvement in child care.

It is complicated to interpret correlations of children and earnings as a causal effect of children because parenthood might be endogenous with respect to earnings or correlated with unobserved factors. Credible instrumental variables that can address these potential problems are difficult to find for fertility. IV has been applied to estimate the earnings effect of the increase in number of children from two to three (Angrist and Evans, 1998), teenage pregnancy (Hotz et al., 2005), and delay of motherhood (Miller, 2011). A caveat of these estimates is that effects at particular parity may not be generalizable to other parities. The most common approach in the literature has been to apply fixed-effects estimation exploiting longitudinal panel data following individuals over time.

In this study, we follow this literature but apply an alternative approach to estimate the mean effect of children on earnings. We compare men's outcomes to those of their brothers or twin brothers over the most important part of their life cycle and before and after entry into fatherhood. We estimate the effect of first entry into fatherhood, allowing the effect to be non-linear. The variation identifying the effect of children comes from pairs of brothers where one becomes a father and the other

\footnotetext{
${ }^{3}$ Statistics show that unadjusted male-female earnings differentials still remain significant, between 15 and 23 percent, and have remained surprisingly stable in many countries over recent decades. Blau and Kahn (2006) show the slowing down of convergence for the U.S. in the 1990s. For an international overview, see Tijdens and Van Klaveren (2012).
} 
never does. While this exercise is in itself interesting, it also potentially addresses some problems in this literature. We exploit that brothers are genetically more similar than randomly selected men from the population and hence the comparison of earnings, holding standard characteristics constant, reduces the heterogeneity problem. We estimate various family fixed factor models that also control for the age differences between brothers, to account for more heterogeneity in family background. Heterogeneity in family background within families may capture nurture effects, such as parenting skills. Using twins offers the advantage that we directly control for family fixed factors, time fixed factors and individual fixed factors. Furthermore, we extend existing earnings models in this literature by controlling for the fact that men who remain childless and men who become fathers-at-some-point may be on different earnings paths from first entry into the labour market; that is when we compare the earnings paths of childless men to those of fathers-at-somepoint even before they enter fatherhood.

To implement the approach we use a large, high quality Norwegian registry data set of the population of brothers and twins born during the period 1955 to 1965 and followed until 2005. Core to our study is that we observe complete employment and earnings histories from first entry into the labour market. This also includes the complete timing of births histories for every individual in the population, employment and earnings before and after childbirths and the link to match brothers. These data offer several advantages over previous studies. The literature on the effect of children on earnings has relied on much smaller samples, mostly, from survey data that do not permit to follow every worker over the complete life cycle in the labour market, observe exact timing of births and complete fertility, and match siblings. Related to our approach, Simonsen and Skipper (2010) exploit Danish data on a sample of twins in 2006, but they estimate more restricted models than we do and cannot distinguish childless men from not yet fathers. They find a significant wage 
premium for men. Neumark and Korenman (1994) analyzed the effect of children on earnings using a relatively small sample of sisters from the NLS for the early 1980s. They did not analyze men. Our approach is also related to studies that exploit genetically identical twins to estimate the marriage premium (Antonovics and Town, 2004; Krashinsky, 2004). In this literature samples are often small and a much discussed problem is attenuation bias because of measurement error in survey data (Bound and Solon, 1999). Therefore, the data we use have an advantage since register data contain process collected information and a large number of individuals.

The remainder of the paper is organized as follows. Section 2 provides an overview of why children may have an effect on earnings for men. Section 3 presents background on the Norwegian labour market and institutions, and the description of the data and summary statistics. Section 4 outlines the empirical framework. Section 5 presents the empirical results. This is followed by the discussion of the empirical approach and a summary of the main results. Section 6 concludes.

\section{Men's earnings and having children}

It is complicated to interpret empirical correlations of children and earnings as a causal effect of children, because parenthood may be endogenous with respect to earnings or correlated with unobserved fixed factors. Human capital theory would predict no effect in the periods post becoming a father since, as the data show, men do not typically take time off to care for children and tend to work full-time for most of their working lives. ${ }^{4}$

\footnotetext{
${ }^{4}$ In general, male labor force participation rates in industrialized countries have declined since the 1970s, while the work pattern whereby men work full-time has remained unchanged (see Blundell and McCurdy, 1999). Studies using U.S. time-use data have shown that time allocation between leisure and work has changed somewhat, with more hours allocated towards leisure.
} 
Given that husbands' and wives' labor market outcomes are interdependent, we would expect the reallocation of mothers' time and effort after childbirth from market to home to be accompanied by some labor market response among fathers. Two explanations discussed in the literature suggest that there is a causal effect of children for men. If the mothers specialize more in home production, this can lead to an increased specialization of fathers in market production, particularly, if mothers also take over other household activities previously conducted by the partner because of economies of scale effects. An earnings increase can also be caused by preferential treatment by employers of fathers, or positive discrimination. For the U.S., studies have shown that part of the child premium is related to increased hours of work (Pencavel, 1986; Lundberg and Rose, 2002).

A third explanation is that earnings advantages of men with children compared to childless men may capture decisions made earlier in life related to the plan to become a father. This explanation suggests that the correlation between children and earnings is due to omitted variable bias. If men expect to make gains in the labour market after child birth, then it is optimal for them to already more invest into their career before they become fathers. There are several potential reasons for why initial earnings and returns to experience may be relatively higher for men who become fathers at some point. For instance, the planning of the timing of births could contribute to the observed patterns (Bergstrom and Schoeni, 1996). Moreover, men who plan to become partners may also self-select into higher-track occupations (Gould, 2008).

A related question is whether cohabitation or marriage even before actually becoming a father explains the relatively higher earnings growth of fathers-at-somepoint (Peters and Siow, 2002). ${ }^{5}$ One hypothesis is that marriage itself leads to

\footnotetext{
${ }^{5}$ Studies of the marriage premium in male wages provide little insight into the effect of having children, since either the effect of having children is not separately reported (Korenmark and Neuman, 1991; Gray, 1997), or is reported to be insignificant (Loh, 1996).
} 
gender-specific household specialization, whereby men specialize more in market work and women in home production. An alternative hypothesis is that men with relatively high productivity-related skills are more likely to marry. A large group of international studies has shown that married men earn between 10 and 40 per cent more than comparable single men (Korenman and Neumark, 1991; Ginther et al., 2001). However, the precise nature of the effects remains unclear. Time-use data offers little support for the specialization hypothesis (Hersch and Stratton, 2000). Time-use data suggests that gender-specific household specialization is not related to cohabitation or marriage, but rather to the presence of children and particularly to when more time is spent on child care (see Dribe and Stanfors, 2009; Hodges and Budig, 2010).

Most previous studies on the effect of children on men's earnings rely on individual fixed effects estimates, ranging between 3 and 10 per cent per year, varying somewhat depending on the country and model specification (see Lundberg and Rose (2000; 2002), Pencavel (1986), Waldfogel (1998), Killewald (2013), Glauber (2008), Hodges and Budig (2010) for the US, Blomquist and Hansson-Brusewitz (1990) for Sweden and van Soest et al. (1990) for the Netherlands). Only a limited number of studies have looked at both the effect of having children and the effect of marriage (Loughran et al. (2009), Hodges and Budig (2010), Hundley (2000), Lundberg and Rose (2002)).

Our study contributes new empirical evidence to this literature by using new data and estimating a more flexible earnings model. We investigate the extent to which controlling for family fixed factors in different ways in earnings equations can help to account for unobserved heterogeneity. For comparison, ordinary least squares and individual fixed effect estimates of the effect of children are presented. The specification allows the effect of children to be non-linear, whereby post-childbirth earnings may shift upward and vary with work experience since en- 
try into fatherhood. We also test whether the effect of children works through first childbirth or higher parity child births and whether the effect of children captures effects through marriage.

A limitation of our study is that we cannot fully account for the fact that, if the timing of fatherhood is anticipated, this may affect earnings and earnings growth before entry into fatherhood. We address this problem in two ways. First, potentially self-selection into the group of fathers works through family fixed effects. In this case, family fixed factors are predictors of individual earnings levels and earnings growth. ${ }^{6}$ Second, the effect of children is estimated after controlling for differential entry earnings and differential returns of work experience (squared) for fathers-at-some-point compared to childless men. This approach controls for differences in earnings paths, namely if fathers started on different (higher) earnings paths to childless men. Hence, these controls potentially reduce the omitted variable problem. None of the studies in the literature addresses this point.

\section{Background, data and summary statistics}

\subsection{Background}

As a background for our analysis, we provide a brief overview of the main features of the Norwegian labor market relevant for our analysis of men's earnings during the period 1975 to 2005 . The Norwegian labor market is characterized by centrally coordinated wage bargaining and high wage compression. Internationally, Norway ranks high in terms of gender equality and family friendliness during recent decades. Gender wage gap indicators show a quite stable difference of 15 percent in Norway,

\footnotetext{
${ }^{6}$ This resembles findings in the literature on the return to education showing that pre-market education predicts wages and wage growth.
} 
which is low compared to Germany and the US (20-23 per cent), for example. ${ }^{7}$ Male labor force participation is high and men typically work full-time, which is defined during recent periods as working 37.5 hours per week. Female labor force participation is also high by international standards, but a number of women with young children work part-time. Norway underwent a severe recession during the period from 1987 to 1993, with unemployment peaking at 67 per cent in 1993.

It has been a long-standing policy goal in Norway to achieve high gender equality and help families to combine having children and work. The main policies to achieve these goals have been anti-discrimination laws introduced during the 1970s, parental leave and child care. Parental leave was first introduced in the 1970s, and a major reform took place in 1993 when leave was extended to 42 weeks at full compensation, while four weeks were reserved to the father (paternity leave). Prior to 1993, virtually no fathers took leave, but almost 80 percent of mothers took the maximum amount. ${ }^{8}$ Since 1993 , the proportion of fathers taking up leave has steadily increased from an initial 30 percent to almost 60 per cent in 1998. During paternity leave, men receive a wage replacement up to a cap. During the 1970s, publicly funded child care programs were expanded for 3 to 6 year old. Between 1990 and 2006, child care programs were also expanded to full coverage for 1 to 2 year olds. Norway has a relatively similar family policy program to the other Scandinavian countries.

\subsection{Data description and summary statistics}

The panel data for sibling and twin men born between 1955 and 1965 is extracted from Norwegian registry data for the period from 1975 until 2005. We focus on these birth cohorts to ensure that we can observe the complete individual earnings

\footnotetext{
${ }^{7}$ These are the unadjusted gender wage gaps reported by Eurostat and the US Census.

${ }^{8}$ The remaining women were not eligible. Workers are eligible if they have been working for 6 out of 10 months before the date of birth.
} 
and employment histories from first entry into the labour market, and fertility histories. The Norwegian multi-generational birth registry was used to match sibling and twin brothers to each other and their offspring. The sample of brothers includes the population of men born between 1955 and 1965 who were the first- or secondborn son within a family with the same mother and father. ${ }^{9}$ The sample of twins includes the population of twins of the corresponding birth cohorts. Fraternal and monozygotic twins are included but cannot be distinguished in the data. ${ }^{10}$

Pulling from a data set dating back to 1967, we generate work and earnings histories from first entry into the labor market. This ensures that we measure entry earnings accurately for every individual in our sample. The main outcome variable is the logarithm of real annual earnings that we use to measure earnings from work. ${ }^{11}$ We deflate earnings by the Norwegian consumer price index $(1998=100)$. Earnings are excluded for workers younger than 20 years of age, as they may still be in education. We also exclude observations with very low earnings (earnings less than the annually adjusted basic income according to the social security system). Years of experience are measured as the cumulative number of years with earnings above the yearly basic income. We calculate this from first entry into the labor market, as well as from first childbirth. We merge age and years of education to the data. We generate a variable measuring the birth order within the family, which we use as a control variable in our earnings regressions. ${ }^{12}$

From the birth registry, we obtain the complete record of the timing of offspring

\footnotetext{
${ }^{9}$ This means that we keep the main group but exclude sons from one-child families, as well as those from families with fewer than two boys.

${ }^{10}$ Statistically, approximately 30 percent of all twins are monozygotic. Only monozygotic twins are genetically 100 percent identical at birth. Siblings are genetically more similar than two randomly selected men.

${ }^{11}$ The earnings variable measures all taxable earnings, including unemployment insurance, disability benefits, parental leave, and sick pay, but not means-tested social assistance and interest on financial assets.

${ }^{12}$ We keep information on birth order within the family, counting both girls and boys. Birth order effects have been documented with Norwegian data in Black et al. (2005).
} 
and the complete number of offspring for every man, counted by $2005 .{ }^{13}$ Note that fathers are reported in the birth registry when they are cohabiting with or married to the mother. In the estimations, we will mostly focus on the effect on the outcome following the year of the first childbirth, which will be referred to as the "post birth period.' For supplementary results, we also use the birth year of the second and third child. Our main group will be fathers-at-some-point, which includes all men for whom we observe a first child in the birth registry at some point in the observation period. The group of men without any children in the birth registry are denoted as childless men, namely those who will never have children.

We assume that virtually all births for the cohorts in the analysis samples are counted, since men in the sample are followed over most of their life cycle, that is, until they are 50 years old, and the youngest cohort until they are 40. Approximately 20 per cent remain childless by the year 2005 , according to the data. National statistics show that the fraction of childless men only declines by 2 percentage points between the age of 40 and 45 , and by 0.6 percentage points between 45 and $50 .{ }^{14}$

We use information on marital status to restrict the comparison group of childless men to men who are childless but married-at-some-point. ${ }^{15}$ Childless men may be a very heterogeneous group, and childless men married at some point may be more similar to fathers-at-some-point at the beginning of their working career. Some of those who married may have planned to become fathers but for some reason did not realize such a plan. ${ }^{16}$ Data on marital status is available for the period 1986 to 2005 and used to construct an indicator for being married at some point (until 2005). We define married-at-some-point as equal to one if a man is ever re-

\footnotetext{
${ }^{13}$ The birth registry is complete, with the exception that the father is not reported if the mother does not want to report him. One birth cohort is around 60,000 in Norway. During the observation period, only 400-500 children were adopted per year and we have no information about those.

${ }^{14}$ The distribution of the number of children in our sample is reported in the Appendix in Table A1.

${ }^{15}$ We do not have access to information on cohabitation for men without children. Hence, we may exclude too many men by this rule.

${ }^{16}$ In our empirical analysis, we have to assume that this is not due to health problems.
} 
ported as married, divorced or separated, and zero otherwise. In order to disentangle whether earnings increases are related to children ${ }^{17}$ or marriage, we also construct a control variable based on the same information concerning whether a man is married in period t. Hence, for fathers-at-some-point, we can control for whether the couple is married before, at or after childbirth. For childless married-at-some-point men, we can control for potential changes in earnings after the time of childbirth.

Tables 1 and 2 here

Tables 1 and 2 report the sample means and standard deviations for the main variables separately for fathers-at-some-point, the comparison group childless men and the restricted comparison group of childless men married-at-some-point. The unconditional difference in mean log earnings between fathers and childless men is 17 per cent for the sample of brothers and 15 per cent for the sample of twins, when we pool all observations across the entire observation period. Compared to childless men, men with children acquire slightly more years of education, and work less. Differences become smaller when we compare fathers to childless men married at some point.

\section{Empirical Framework}

We assume that the log earnings, $\ln y_{i f t}$, for individual $i$, in family $f$, and calendar year $t$ is given by:

$$
\ln y_{i f t}=\gamma_{t} a_{i f t}+\beta^{\prime} X_{i t}+\delta^{\prime} Z_{i f t}+\nu_{f}+\mu_{i f}+w_{i f t}
$$

where $a_{i f t}$ is equal to one from the time a person first enters fatherhood, and zero otherwise, $X_{i t}$ includes controls for years of education and experience (squared)

\footnotetext{
${ }^{17}$ The father is reported on the birth certificate if he is married to or cohabiting with the mother.
} 
counted since entry into the labor market, $Z$ contains the indicator variable equal to one if the man is a father-at-some point and its interaction terms with years of experience (squared) since entry. The error term contains three components: an unobserved family fixed component, $\nu_{f}$, capturing genetically inherited ability ${ }^{18}$; an individual varying and family-varying unobserved component, $\mu_{i f}$, capturing unobserved ability and genetic traits that vary across individuals and families; and $u_{i f t}$ capturing other idiosyncratic variation (or luck).In addition, in the empirical estimation, we control for birth order effects capturing that first or second born brothers within a family differ in birth order rank, as well as time-varying factors, $\tau_{t}$, capturing macroeconomic shocks. ${ }^{19}$ We assume that $E\left(w_{\text {ift }} X_{i t}\right)=0$ and $E\left(w_{\text {ift }} Z_{\text {ift }}\right)=0$ for all $i, f$ and $t .^{20}$ The key parameter is the marginal effect of having children, $\gamma_{t}$, and to make it more flexible, we allow the effect to be a non-linear function in $a_{i f t}$ and post-birth work experience, $e x_{\text {post }}:^{21}$

$$
\gamma_{t}\left(a_{i}, e x\right)=\gamma_{t 1} 1(a=1)_{i t}+\gamma_{t 2}\left(e x_{p o s t}\right)_{i t}+\gamma_{t 3}\left(e x_{p o s t}^{2}\right)_{i t}
$$

As a baseline, we estimate the earnings regression by ordinary least squares And, to follow the literature, we present fixed effects (FE) estimations exploiting the panel structure of the data and within individual variation. ${ }^{22}$

\footnotetext{
${ }^{18}$ Since we cannot distinguish identical twins from fraternal twins we cannot use their comparison to disentangle nature and nurture effects. Another reason why we want to control for family fixed factors is that they are potentially correlated with fertility outcomes if, for example, families pass on fixed values to their offspring that are important traits for having a family later in life (Fernandez and Fogli, 2006).

${ }^{19}$ As a supplement, we show that the earnings equation can be derived in a treatment framework as suggested in Heckman and Hotz (1998). See Appendix B.

${ }^{20} \mathrm{We}$ follow the common assumption in the literature, but acknowledge that it might be restrictive to assume no reserve causality. Identification depends on this assumption for both the family fixed estimator and the individual fixed effect estimator. Only instrumental variable estimators can be employed to relax this assumption.

${ }^{21}$ This may capture time varying costs of children, or effects through further children.

${ }^{22}$ Since individual fixed effects (FE) sweep out all time constant variables, it cannot identify the differential effect of entry earnings between the group father-at-some point and childless men. FE will give a consistent estimate of $\gamma$ if $a$ and $w$ are uncorrelated. A common concern with this type of model is that estimates are biased if past earnings affect current fatherhood status.
} 
Our main estimation results rely on the covariance estimator (CV)(Bound and Solon, 1999), which applies ordinary least squares to the regression of the betweensiblings differences in log earnings in every period on the between-siblings difference in the children variables, holding other between-sibling differences constant. It exploits the cross-sectional variation for identification. If we assume $\mu_{1 f}=\mu_{2 f}^{23}$, then the transformed regression can be written as:

$\left(l n y_{1 f t}-\ln y_{2 f t}\right)=\gamma_{t}\left(a_{1 f}-a_{2 f}\right)+\beta^{\prime}\left(X_{1 f t}-X_{2 f t}\right)+\delta^{\prime}\left(Z_{1 f t}-Z_{2 f t}\right)+\left(w_{1 f t}-w_{2 f t}\right)$

The between-sibling difference is always formed by subtracting the variable of the second-born brother in family $f$ from the variable of the first-born brother in family $f$.

Variation used to identify the parameters $\delta$ and $\gamma_{t}$ comes from sibling pairs where one sibling has children and the other does not. To identify $\delta$, we need variation in $a$, which is independent of $Z$; that is, we need to observe men in the group of father-at-some-point before they actually become a father. ${ }^{24}$ This highlights the value of the data in which we observe the complete employment, earnings and fertility histories for the selected cohorts and completed fertility for every man in the sample. We also need that $a$ and $Z$ are uncorrelated with $w$.

The advantage of our approach is that when we compare two men from the same family (same mother and same father), they are more similar in terms of the unobserved component than two randomly selected men from the population. However, this comparison may still lead to a biased estimate of the effect of children in

\footnotetext{
${ }^{23}$ Since we cannot make use of data on monozygotic twins, we cannot sweep out the $\mu$ completely and therefore have to make assumptions. We also tested whether $\mu_{1 f}=\mu_{2 f}=0$. We tested for second and third order serial correlation of the error term from the model in between-sibling differences, observing that serial autocorrelation remains, yet is small. The correlation coefficients are 0.085 .

${ }^{24}$ At the individual level, $i$, all combinations of $Z$ and $a$ are observed, except for the combination $Z=0$ and $a=1$, i.e. childless man after becoming a father
} 
our model, since we cannot claim that $\mu_{1 f}$ is exactly equal to $\mu_{2 f}$ when we use all brother pairs. We can still reduce unobserved heterogeneity problems by using within family variation, if the family fixed factor is correlated with fertility outcomes. If family environment is also related to parenting skills and these differ between brothers who are very different in age, we can more accurately control for family fixed effects when the siblings are more similar in age. Possible reasons why brothers who are very different in age vary relatively more in terms of family background than brothers born only one year apart could be that parents are in different career phases, may differ in terms of time and monetary resources or have different experience duration in parenting. We take advantage of our large sample and run separate regressions on sub groups of brother pairs who are more similar in age. Naturally, twins are exactly equal in terms of age and parenting skills.

In addition to the estimation results, we provide statistics on the correlations of fertility, estimates on sub-samples to explore the importance of family fixed effects versus composition effects, the bias by a comparison of OLS, FE, as well as the series of $\mathrm{CV}$ estimates.

\section{Empirical Results}

\subsection{The mean effect of having children}

Table 3

In Table 3, we present the estimation results of the effect of having children on earnings estimated by OLS, FE and CV (covariance estimator). The table shows the key coefficients on the effect of children in the lower panel, while all coefficients of the control variables are shown in the two upper panels. The parameter estimates of the auxiliary variables have the expected signs and sizes. The OLS estimates on 
the pooled sample of brothers (column 1) show that the conditional effect of having children on earnings at birth is 7.3. and quite large and positive. The marginal post-birth effect in experience is U-shaped and tends to increase.

When we estimate the model by individual fixed effects, the coefficients of the variables of having children (column 2) decrease compared to the OLS coefficients. ${ }^{25}$ The shift parameter right at birth decreases by more than a third. The marginal effect post-birth is convex and becomes zero around 2.8 years after first childbirth, before remaining negative across relevant values of experience.

Column (3) in Table 3 reports the results from the covariance estimator (CV) on the same sample, whereby all brother pairs are pooled. ${ }^{26}$ They show that earnings significantly increase in the birth year of the first child, but now the point estimate of the shift right after childbirth is 6.4 percent. The marginal effect post-birth is slightly U-shaped, but increasing. For illustration, the model estimates show that 14 to 35 percent of the simple OLS estimated effect of children one year after childbirth is due to positive selection on fixed family-specific and fixed individual unobserved factors. Selectivity on fixed family-specific factors appears significant but relatively small when we use variation from all brother pairs. ${ }^{27}$

Siblings might still be quite heterogeneous in terms of family background, which may introduce bias and thus make family fixed factors appear less important. Siblings are genetically more similar than randomly selected men, but are not genetically identical, unlike monozygotic twins. Siblings also differ due to differences in the timing of parenting (nurture). Parents' skills and resources develop over time, and the older sibling in our sample is 3.5 years older at the mean.

\footnotetext{
${ }^{25}$ For all fathers-at-some-point, earnings are observed before having a child.

${ }^{26}$ Summary statistics for the variations in between-sibling differences are also presented in Table A2 in Appendix A, showing that the variations in differences between siblings and twins are still large enough.

${ }^{27}$ The coefficients of the pre-birth differential effects between fathers-at-some-point and the group of childless men reported in the upper panel of Table 3 are quite large and significant. This suggests that fathers-at-some-point start on higher growth earnings paths than childless men.
} 
In order to control for the potential timing of parenting differences between siblings, we re-estimated the regressions on the sub-samples of brothers who are born two years or less apart and one year or less apart (see Table 3 columns (4) and (5)). Results using the twin sample completely remove effects due to age differences (see column (8)). Gradually reducing the age differences between brothers leads to a reduction in the coefficients measuring the effects on post-birth earnings of having children. The effect on earnings of having children right after childbirth declines to +4.0-4.1 per cent, from an initial +6.4 per cent. From the second year after birth, the effect remains constant. ${ }^{28}$ When twins are used, the effect post-birth declines even further. The adjustment of earnings post-birth is now a constant shift of 2 per cent, but is not significant.

The decrease in the effect of children in this model is driven by the fact that using twins allows us to control for time effects, family fixed effects and age in the best way, given that they are born in exactly the same year. ${ }^{29}$ Note that the mean pair is now genetically more similar, because some twins in the sample are monozygotic and hence genetically identical at birth. ${ }^{30}$ The F-test shows that estimates from brothers one year different in age, or less, and twins are jointly significantly different (Table 3 column 5 compared to column 8).

We explore further reasons why the effect of children remain relatively large for the sample of brother pairs only one year, or less, different in age compared to twins. First, we use childless men married-at-some-point as an alternative comparison group. ${ }^{31}$ The summary statistics on mean earnings and education show that

\footnotetext{
${ }^{28}$ Only the coefficient of the experience squared variable is significant in column 4 , but it is economically small.

${ }^{29}$ All of the estimates using childless men as the comparison group reveal significantly larger returns to experience of fathers-at-some-point compared to childless men even before first entry into fatherhood. CV on the twin sample shows that entry wage differentials remain quite large.

${ }^{30} \mathrm{We}$ cannot tell whether the genetic component drives our results since we cannot distinguish between fraternal and monozygotic twins in our data.

${ }^{31}$ The twin sample would become substantially smaller when we further restrict them, which is why we explore the following factors using brothers excluding twins.
} 
men in the group fathers-at-some-point are indeed more similar to childless men married-at-some-point than to all childless men. Table 4 columns 1 and 3 report the new estimation results using the restricted comparison group. The size of the effects post-birth do not change significantly compared to the results in Table 3 columns 2 and 5.32

Table 4 here

We also want to test whether the estimates are driven by childbirth or relatively more by marital status. Following the literature, we therefore add a control variable for actually being married. We run these regressions again using the samples of brothers and the restricted comparison group, since the samples of twins would become too small. Note that men in Norway typically marry after becoming a father. As shown in Figure 1, approximately 3 out of 4 couples get married close to the time of first childbirth or later in our sample. ${ }^{33}$

Figure 1 here

The estimation results reported in Table 4 columns 2 and 4 show that adding a control for being married only slightly reduces the size of the effect on earnings of having children. ${ }^{34}$ Looking at the regression results in Table 4 column 4 for brothers who are only one year different in age, the effect of children is 3.2 percent and economically constant. These results confirm that the larger part of the estimated positive effect of having children remains after we account for marriage,

\footnotetext{
${ }^{32}$ The coefficients of the pre-birth differential effects between fathers-at-some-point and the restricted group of childless men reported in the upper panel of the table are now much smaller than those reported in Table 3, but are still significant. This suggests that the large differences found in Table 3 are driven by childless men who are never married and perform worse.

${ }^{33}$ Note that since marital status is only available since 1986, we have a slight over-reporting of unmarried men in the pooled sample.

${ }^{34}$ Technically, all men not married at childbirth but reported in the birth register are cohabiting. Therefore, the effect of children is the joint effect of post-first childbirth and cohabiting. However, note that the results now show that, before birth, fathers-at-some-point are on very similar earnings paths to the restricted group of childless men. Hence, even if some men already cohabit before having children, the effects possibly related to household specialization or selection into the fatherhood group at least seem quite small. This pattern is in line with recent time use data for Norway (See Appendix C Table C1).
} 
$(28$ percent $=1-(0.032 / 0.044) * 100) .{ }^{35}$ The relatively small effect of marriage can also be seen from Figure 2, where the simulated earnings profiles of a hypothetical father-at-some-point is plotted, comparing the two estimates with and without a control for being married. These results appear plausible in the context of a Scandinavian society where gender equality is high and marriage traditionally takes place after the first childbirth. Married and cohabiting couples are treated equally under Norwegian law, including tax laws.

Figure 2 here

It is also possible that the effects after the first childbirth capture the effects of second or further births. In extension, we add dummy variables and the corresponding interaction terms with experience (squared) for second and third births to our preferred model. We re-estimated the model for the brother sample used in Table 4 column 4. As seen from Table A3 in the appendix, our previous results remain unchanged and the effects after the second and third birth are not significant. ${ }^{36}$

\subsection{Discussion of the estimation approach}

It might be surprising that fertility and fixed family factors are correlated, given that fertility choices are made relatively late in life. For comparison, it has been widely shown that educational choices taken relatively early in life are highly correlated with family fixed factors, as well as highly correlated between siblings and twins (e.g. Ashenfelter and Rouse, 1998). As we can see from Table 5, fertility outcomes

\footnotetext{
${ }^{35}$ In this calculation, we ignore the curvature parameters, since they are virtually zero.

${ }^{36} \mathrm{As}$ an additional test of the robustness of our findings, column 3 in Table A3 reports results when we drop earnings following births that took place during the period when paternity leave was available. In 1993, four weeks of parental leave were reserved to fathers for the first time, which led to the effect that some fathers interrupted work for an additional month. In order to ensure that potential negative earnings effects through interruptions related to becoming a father do not affect our findings, we ran regressions on a restricted sample. As can be seen, the main results are unchanged. For studies on the paternity leave reform, see Rege and Solli (2010). Table C2 in Appendix C reports the complete replication results on the restricted sample.
} 
in our data are significantly correlated between siblings and correlation coefficients are quite large, at between 11 per cent and 24 per cent. The correlation between two randomly selected men from the population is zero. By comparison, the correlation in years of education for twins is 51 percent and hence, as expected, is higher. ${ }^{37}$

Table 5 here

Identification applying the covariance estimator depends on sibling pairs where one brother has children and the other does not. At the mean in our sample for brothers, 27.94 per cent of all siblings have the combination 'no children' and 'children', whereas 73.06 percent of brothers either both have children or both have none. For twins, the corresponding values are 25.73 and 74.27. The panel of graphs in Figure 3 plots the percentage of pairs for whom both brothers have children or neither has children separately across years, years of education and years of experience. The proportions are constant across years, which is reassuring for our identification strategy.

Figure 3 here

It is possible that sibling pairs that identify the effect of having children in the family fixed effects model estimates are different from the random sibling pair in our sample, which could drive the results. In order to investigate this possibility, we present means and standard deviations for the sample of sibling pairs where only one sibling has children and the other does not (unequal fertility outcomes). The means of the main characteristics presented in Table 6 are very similar to those of the entire sample. For illustration, we also investigated whether fertility patterns and their correlations with education are different for the total sample and the restricted sample of sibling pairs. As Figure 4 shows, the patterns are very similar at all levels of education, except at very high levels of education where observations are few.

\footnotetext{
${ }^{37}$ Our results appear in line with evidence from the demographic literature that has shown intergenerational transmission of fertility patterns. This automatically leads to a correlation between siblings.
} 
Figure 4 here, Table 6 here

The corresponding regression results shown in Table 7 tend to confirm that our previous results are not driven by sample composition. However, we note a shift in the levels of the estimate of the post-birth effect; both the OLS estimate of the effect of having children and the CV estimate are lower than the estimates reported in Table 3. The shift post-childbirth now is 1.2 percent, and increasing by 0.5 percent per year. Only the slope coefficient is significant.

Table 7 here

As shown in Table 3, FE and CV both indicate an upward bias of ordinary least squares, although the point estimates are very different. One reason might be that the $\mathrm{FE}$ and $\mathrm{CV}$ transformations of the main equation sweep out different sources of variation. The estimates may represent complementary findings. The FE model sweeps out all time-constant unobserved and observed variables using the panel. The CV model takes differences cross-sectionally between siblings in every period

of the life-cycle and then applies OLS, conditional on the set of controls. The large sample allows us to control for family fixed factors in great detail and in various ways, which we consider an advantage over individual fixed effects.

\subsection{Summary of the main results}

The empirical analysis leads us to conclude that accounting for family fixed factors in earnings regressions to estimate the effect of children is a fruitful alternative estimator. Our preferred estimation employs the covariance estimator on flexible earnings regressions and use data from twins.

When we recall the $\mathrm{FE}$ and $\mathrm{CV}$ estimation results on the pooled sample, we observe that they give a non-linear U-shaped effect post-childbirth. In case of FE, this implies that the marginal effect will turn negative after 2.8 years, and it is not 
quite clear what mechanism can explain this pattern. The non-linearity could be related to the age of the child, although the effect should rather be the opposite in this case. The age of the child could capture the decreasing intensity of home production or increasing consumption. In both cases, the effect of children should rather increase over time. Therefore, we expect the marginal post-child effect not to be decreasing.

The estimation results from CV concerning brothers who are one year different in age, or less, as well as twins, give effects that remain constant after entry into fatherhood. Estimates of the mean effect of the first child for brother pairs very similar in age range between 3.2 and 4.4 percent, with both estimates significant at common significance levels. We prefer the lower estimate that controls for marriage. When we use twin pairs, the estimated effect is 2 per cent, but is not significant.

In Norway, almost all women took paid parental leave between 24 and 42 weeks after childbirth and return to work afterwards during the period of observation. Therefore, it is not clear whether parental leave in itself translates into permanent changes, such as an adjustment of fathers' labour supply. To analyze this in further detail, longitudinal time series information on household activities would be useful, as well as other information on partners' careers. $^{38}$

The comparison of the family fixed type of estimation results show compelling evidence that family background matters for estimating the effect of children. Since we can control for time fixed effects, family fixed effects and individual fixed effects in the best manner by using twins, we prefer these estimates. The estimate from twins may also still contain small effects through marriage if we extend the results on brothers close in age to twins. We can reject the hypothesis that the effect is

\footnotetext{
${ }^{38} \mathrm{We}$ also tested whether labour supply adjustments, such as working more than 35 hours of work, may contribute to the positive effect post-birth that remains in Table 3 column 5. Estimating the same regressions as for log earnings but replacing the dependent variable, we find small effects through increased hours of work, as well as not consistent findings for employment with a plant. See for the complete results Appendix C Table C3.
} 
driven by further children. We conclude that the earnings effect of children for men is not significantly different from zero. This is an estimate of the mean effect of entry into fatherhood post first childbirth.

The estimation results from twins allow us to conclude that the OLS estimates of the effect of children on men's earnings are upward biased and family sorting is an important contributing factor. Accordingly, individuals with relatively high values of the family-specific factors are becoming fathers, which drives the estimated effect of children upwards. We already see this bias if we use brothers close in age. To illustrate the bias, Figure 5 plots the simulated profiles for fathers-at-some-point for those who become a first-time father after five years in the labor market and who are working continuously. A comparison of the predicted log earnings using OLS (Table 3, column 1) and CV (Table 4, col. 4) reveals that OLS over-estimates earnings of fathers compared to childless men; calculations show that the upward bias is approximately 20 percent around the year of childbirth. Hence, between-family differences account for a substantial amount and men with children have relatively high values of these components.

Figure 5

\section{Conclusions}

In this study, we estimate the effect of children on earnings for men using Norwegian registry data on employment, earnings and fertility histories for cohorts of men born between 1955-1965 who can be matched to their brother. We present a series of individual fixed effects and type-of-family fixed effects estimation results, which also control for differential entry earnings and returns to experience pre-birth.

We find a non-significant effect of children on earnings of 2 per cent per year when only using twins for estimation. This result puts Norway at the lower end of 
the scale of estimates found in the economics and sociological literature. Since education is free in Norway, parents do not need to save for their children's education, most women work ${ }^{39}$ and parental leave is paid. Taken together, this suggests that the labor supply responses are expected to be smaller in Norway than in the US, for example. Indeed, our results are consistent with this hypothesis.

The evidence in this paper adds to the debate about the sources of the gender wage gap. The conventional wisdom is that having children has a negative effect on mothers' earnings and a positive effect on fathers' earnings, which suggests that, all other things being equal, the redistribution of household time and time spent with children would potentially reduce the gender wage gap through a decrease of the premium to men. The results in this study highlight that the observed child premium for men is an upward biased estimate of the direct effect of children on men's earnings. Hence, potential effects through redistributive policies at the household level are potentially less effective than would be expected from observed gender wage gap and family gaps. Therefore, the answer to the question posted in the title is 'yes' for the average man.

\section{References}

[1] Anderson, Deborah, Melissa Binder and Kate Krause (2002): The Motherhood Earnings Penalty: Which Mothers Pay It and Why? American Economic Review, 92(2), 354-358.

[2] Angrist, J.D. and W.N. Evans (1998): Children and their parents' labor supply: Evidence from exogenous variation in family size, American Economic Review, 88(3), 450-477.

\footnotetext{
${ }^{39}$ In 1990 (2009), 62.5 (68.8) per cent of women were working in Norway, compared to 57 (58) per cent in the U.S. Source: OECD.
} 
[3] Antonovics, K. and R. Town (2004): Are all the good men married? Uncovering the sources of the marital earnings premium, American Economic Review, 94(2), 317-321.

[4] Ashenfelter O. and C. Rouse (1998): Income, schooling, and ability: Evidence from a new sample of identical twins, The Quarterly Journal of Economics, $113(1), 253-284$.

[5] Becker, G. S. (1985): Human capital, effort, and the sexual division of labor, Journal of Labor Economics, 3(1), S33-58.

[6] Bergstrom, T. and R.F. Schoeni (1996), Income prospects and age-at-marriage, Journal of Population Economics, 9, 115-130.

[7] Bertrand, M., C. Goldin and L. Katz (2010): Dynamics of the Gender Gap for Young Professionals in the Financial and Corporate Sectors. American Economic Journal: Applied Economics, 2(3), 228-255.

[8] Black, S.; P.J. Devereux, K.S. Salvanes (2005): The more the merrier? The effect of family size and birth order on children's education, The Quarterly Journal of Economics, 669-700.

[9] Blau, F.D. and Kahn, L. M. (2006): The U.S. gender gap gap in the 1990s: slowing convergence, Industrial and Labor Relations Review, 60(1), 45-66.

[10] Blomquist, N. and U. Hansson-Brusewitz (1990): The effect of taxes on male and female labor supply in Sweden, Journal of Human Resources, 25, 317357.

[11] Blundell, R. and T. MacCurdy (1999): Labor supply: A review of alternative approaches, Handbook of Labor Economics, Vol. 3, ed. O. Ashenfelter and D. Card, Elsevier Science B.V. 
[12] Bound, J. and G. Solon (1999): Double trouble: On the value of twins-based estimation of the return to schooling, Economics of Education Review, 18, $169-182$.

[13] Dribe, Martin and Maria Stanfors (2009): Does parenthood Strengthen a Traditional Household Division of Labour? Evidence From Sweden. Journal of Marriage and Family, 71 (February): 33-45

[14] Fernandez, R. and Fogli, A. (2006): Fertility: The role of culture and family experience, Journal of the European Economic Association, 482-3), 552-561.

[15] Ginther, D.K. and Zavodny, M. (2001): Is the male marriage premium due to selection? The effect of shotgun weddings on the return to marriage, Journal of Population Economics, 14(2), 3131-328.

[16] Glauber, R. (2008): Race and gender in families and at work: The fatherhood premium, Gender \& Society, 22, 8-30.

[17] Goldin, C. (2006): The quiet revolution that transformed women's employment, education, and family, American Economic Review, 96(2), 1-21.

[18] Gould, E. (2008): Marriage and Career: The Dynamic Decisions of Young Men, Journal of Human Capital, 2(4), 337-378.

[19] Gray, J.S. (1997): The fall in men's return to marriage. Declining productivity effects or changing selection, Journal of Human Resources, 32(3), 481-504.

[20] Gupta, N.D., N. Smith, L.S. Stratton (2007): Is marriage poisonous? Are relationships taxing? An analysis of the male marital earnings differential in Denmark, Southern Economic Journal, 74 (2), 412-433. 
[21] Hersch, J. and L. S. Stratton (2000): Household specialization and the male marriage wage premium, Industrial and Labor Relations Review, 54(1), 7894.

[22] Hodges, M.J. and M. J. Budig (2010): Who gets the daddy bonus? : Organizational hegemonic masculinity and the impact of fatherhood on earnings, Gender and Society, 24, 717-745.

[23] Hundley (2000): Male / Female earnings differences in self-employment: The effects of marriage, children, and the household division of labor, Industrial and Labor Relations Review, 54 (1), 95-114.

[24] Hotz, V.J., McElroy S.W. and S.G. Sanders (2005): Teenage childbearing and its life cycle consequences: exploiting a natural experiment, Journal of Human Resources, 60(3), 683-715.

[25] Joshi, Heather; Pierella Paci and Jane Waldfogel (1999): The Earnings of Motherhood: Better or Worse? Cambridge Journal of Economics, 23(5), 54364.

[26] Killewald, Alexandra (2013): A Reconsideration of the Fatherhood Premium: Marriage, Coresidence, Biology, and Fathers' Wages, American Sociological Review, 78(1), 96-116

[27] Korenman, S. and D. Neumark (1991): Does marriage really make men more productive? Journal of Human Resources, 26(2), 282-307.

[28] Krashinsky, H.A. (2004): Do marital status and computer usage really change the earnings structure?, Journal of Human Resources, 39, 774-791.

[29] Loh, E.S. (1996): Productivity differences and the marriage wage premium for white males, Journal of Human Resources, 31(3), 566-589. 
[30] Loughran, D.S. and J.M. Zissimopoulos (2009): Why wait? The effect of marriage and childbearing on the earnings of men and women, Journal of Human Resources, 44(2), 326-349.

[31] Lundberg, S. and E. Rose (2000): Parenthood and the earnings of married men and women, Labour Economics, 7, 689-710.

[32] Lundberg, S. and E. Rose (2002): The effects of sons and daughters on men's labor supply and earnings, Review of Economics and Statistics, 84(2), 251268.

[33] Miller, A.R. (2011): The effects of motherhood timing on career path, Journal of Population Economics, 24(3), 1071-1100.

[34] Neumark, D. and S. Korenman (1994): Sources of bias in women's equations: Results using sibling data. Journal of Human Resources, 29(2), 379-405.

[35] Peters, M. and A. Siow (2002): Competing Premarital Investments, Journal of Political Economy, 110(3), 592-608.

[36] Pencavel, J. (1986): Labor supply of men: A survey, in: Handbook of labor economics, Vol. 1, Eds.: Orley Ashenfelter and Richard Layard. NY: Elsevier Science Pub., 1986, 3-101.

[37] Rege, M. and I.F. Solli (2010): The impact of paternity leave on fathers' future earnings, Demography, 50.6, 2255-2277.

[38] Simonsen, M. and L. Skipper (2010): The family gap revisited: What wombmates reveal, Labour Economics, 19, 102-112.

[39] Tijdens, K.G., Van Klaveren, M. (2012): Frozen in time: Gender pay gap unchanged for 10 years. Brussels, ITUC. 
[40] van Soest, A. Woittiez ad A. Kateyn (1990): Labor supply, income taxes, and hours retrictions in the Netherlands, Journal of Human Resources, 25, 517558.

[41] Waldfogel, J. (1998): Understanding the family gap in pay for women with children, Journal of Economic Perspectives, 12(1), 137-156. 


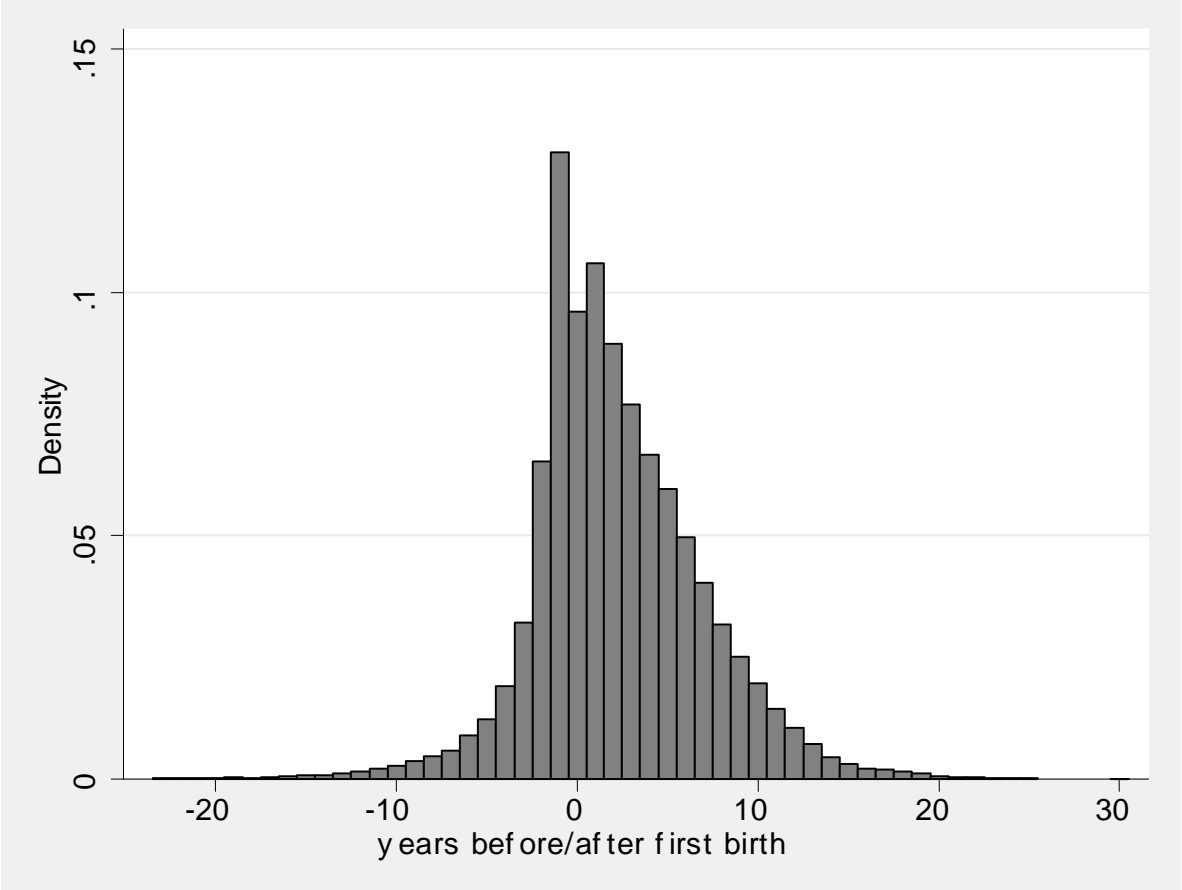

Figure 1: Timing of marriage and first childbirth, own calculations using the sample of all brothers followed from 1986 to 2005 . 


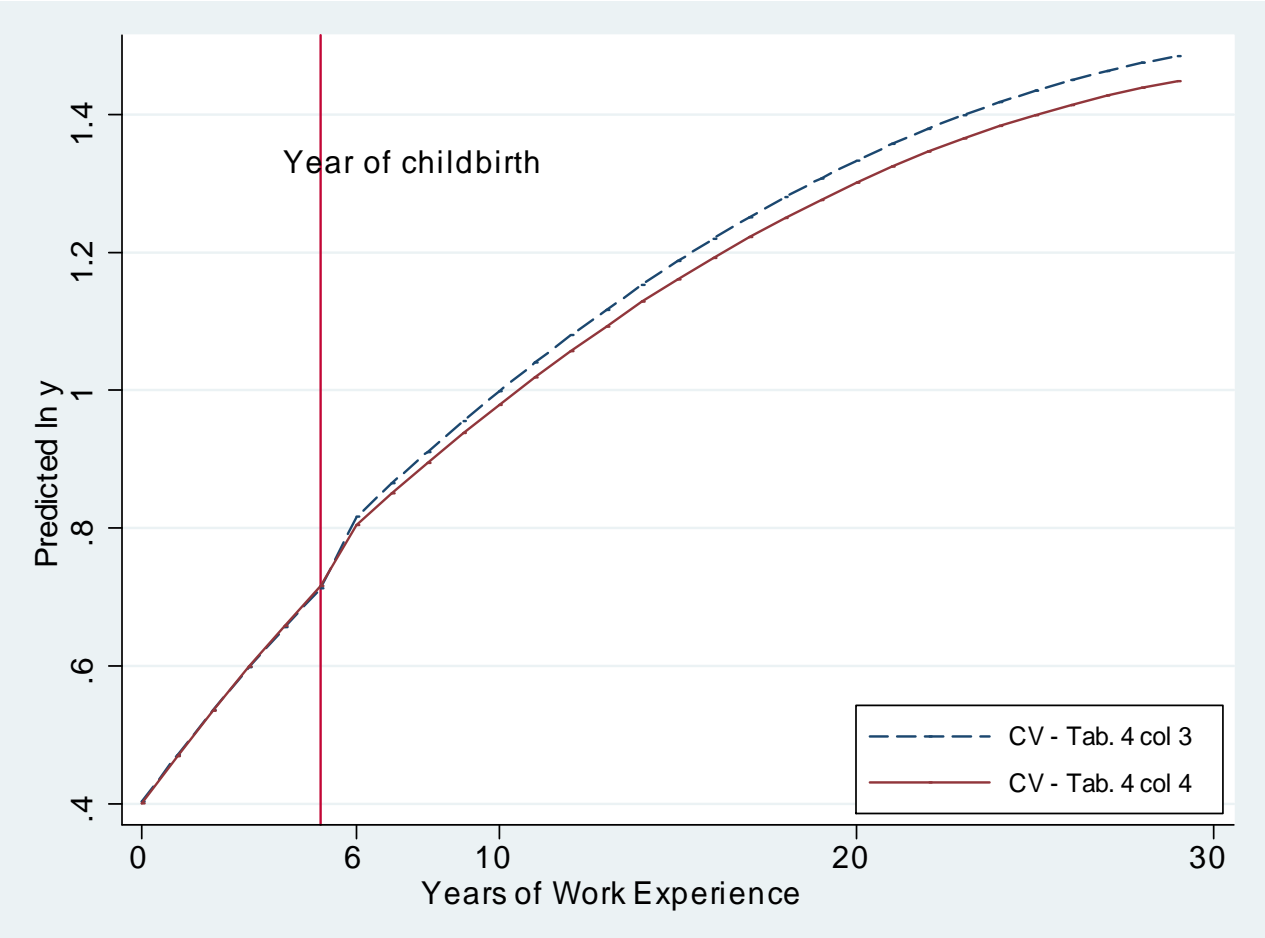

Figure 2: Predicted earnings using estimates of the post-birth effect without (Tab. 4 Col. 3) and with a control (Tab. 4 Col. 4) for being married Note: For illustration a man is used who is continuously working for 5 years since first entry into the labour market, is then entering fatherhood and continues working until 30 years of work experience are completed. 

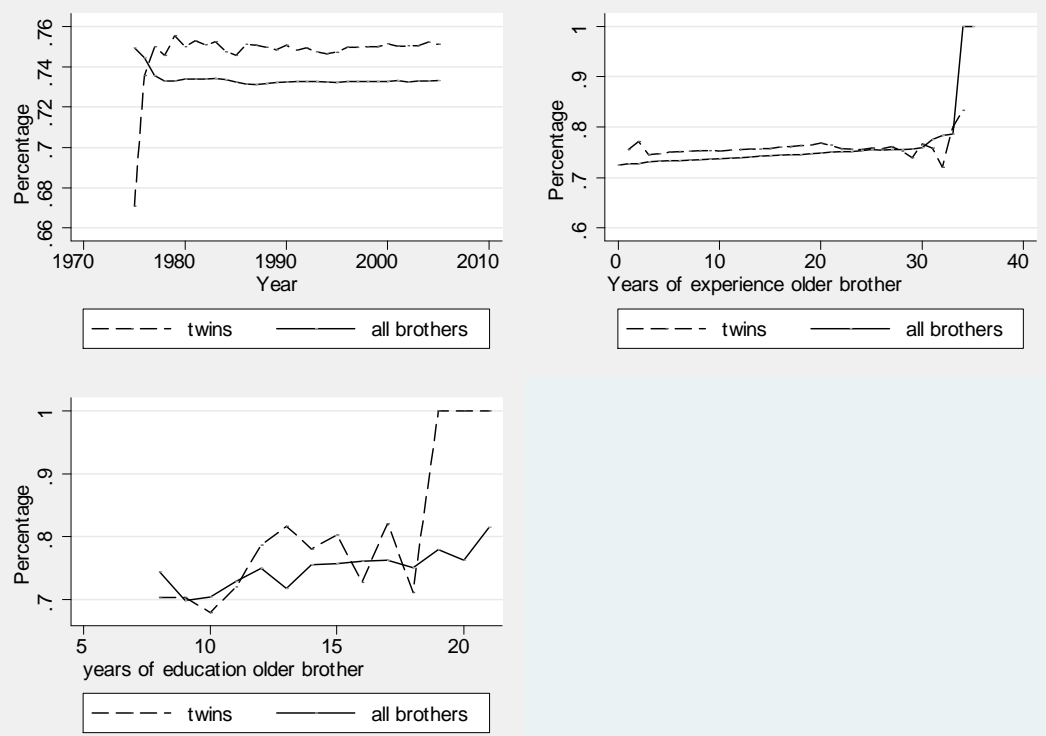

Figure 3: Percentage of brother couples where both of them have children, or both of them have no children
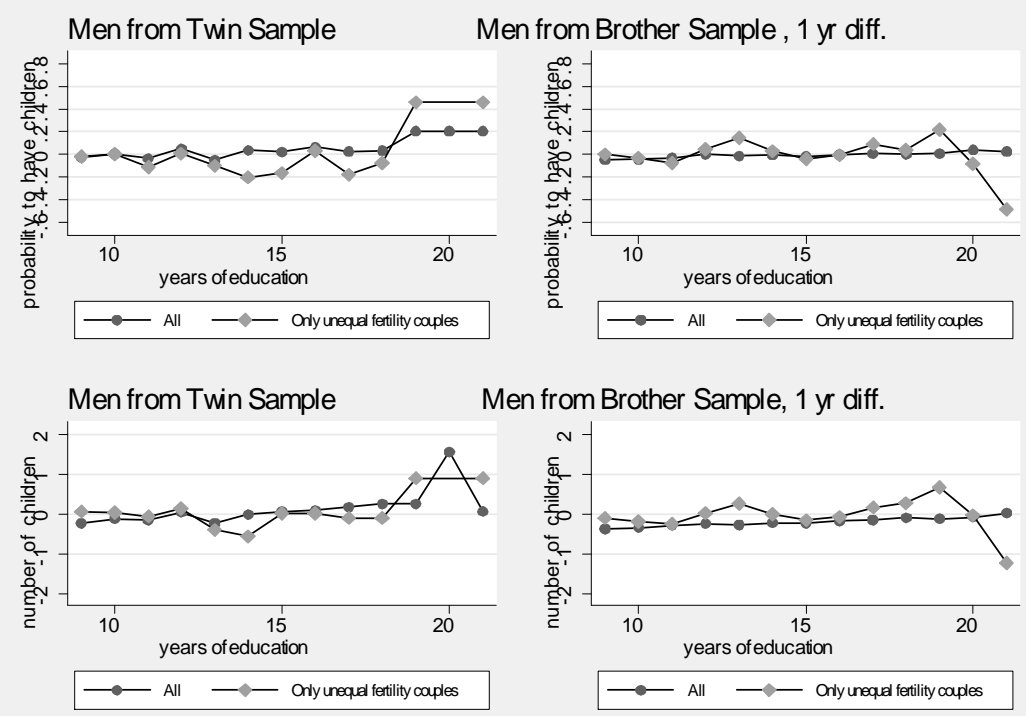

Men from Brother Sample, 1 yr diff.

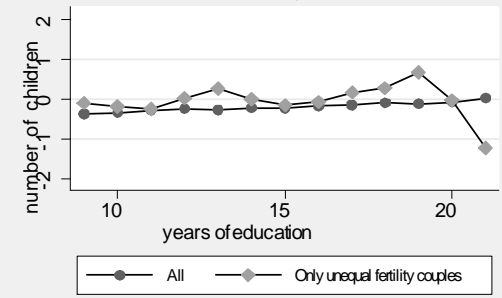

Figure 4: Testing correlation between fertility outcomes and years of education - the normalized graph is shown. 


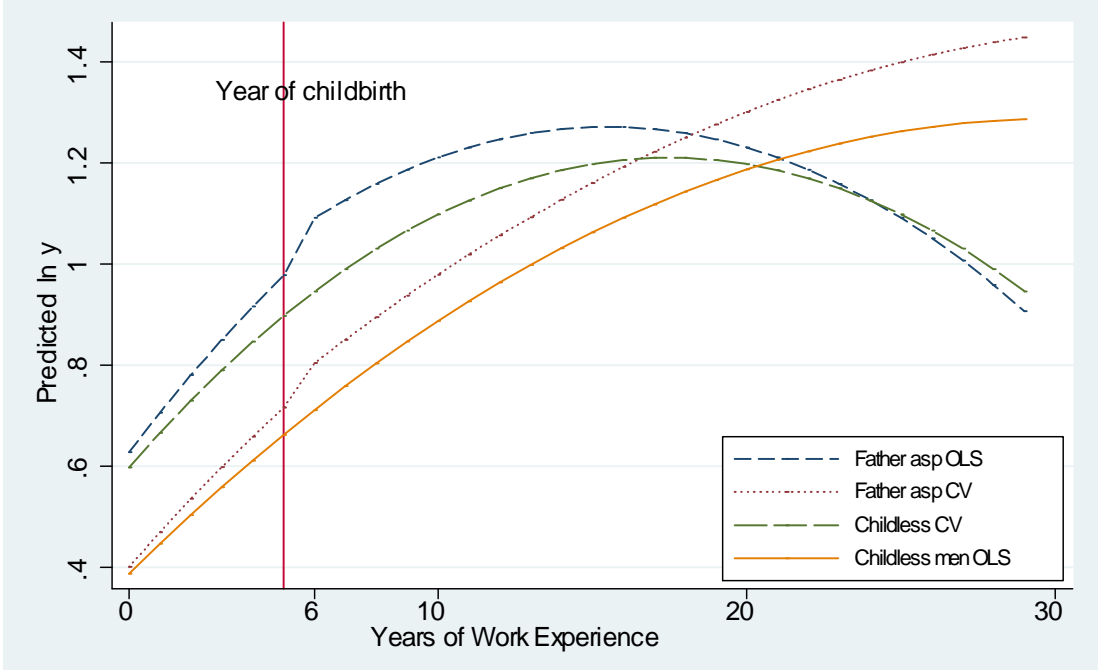

Figure 5: Predicted earnings profiles for a man who is continuously working for 5 years since first entry into the labour market, is then entering fatherhood and continues working until 30 years of work experience are completed. Estimates from Table 3 Column 1 and Table 4 Column 4 are used. See text for explanations. 
Table 1: Descriptive statistics for sibling brothers: Means and standard deviations

\begin{tabular}{lcccccc}
\hline \hline & \multicolumn{2}{c}{ fathers-at-some-point } & \multicolumn{2}{c}{ childless men } & \multicolumn{3}{c}{$\begin{array}{c}\text { childless men } \\
\text { married-at-some-point } \\
\end{array}$} & & & & & & \\
& mean & sd & mean & sd. & mean & sd. \\
\hline log(earnings) & 12.42 & .52 & 12.25 & .52 & 12.33 & .51 \\
real annual earnings (1000 Nkr) & 267.3 & 271.3 & 219.8 & 153.6 & 237.5 & 154.0 \\
yrs of education & 12.28 & 2.47 & 11.90 & 2.59 & 12.04 & 2.54 \\
age & 33.61 & 7.18 & 33.11 & 7.16 & 33.88 & 7.29 \\
age at first marriage* & 30.32 & 4.41 & 34.66 & 6.00 & 34.47 & 6.01 \\
age at first birth & 28.35 & 5.47 &. &. &. &. \\
number of children & 2.38 & .95 & 0 & 0 & 0 & 0 \\
year first job & 1982 & 2.81 & 1982 & 2.96 & 1980 & 3.30 \\
yrs of experience & 13.57 & 7.13 & 12.64 & 7.07 & 13.53 & 7.20 \\
yrs of experience before first birth & 1.82 & 3.81 & 12.64 & 7.07 & 13.53 & 7.20 \\
year of birth & 1960 & 2.98 & 1960 & 2.98 & 1959 & 3.03 \\
Year of birth first child & 1988 & 6.39 & & &. &. \\
Year of birth second child & 1991 & 6.05 & & &. &. \\
married-at-some-point & 0.81 & 0.39 & 0.20 & 0.4 & 1 & \\
number of obs. brothers & 1461807 & & 272249 & & 51351 & \\
\hline \hline
\end{tabular}

Data: Norwegian register data 1975 until 2005. ${ }^{*}$ available since 1986.

Pooled sample of first and second born brothers, excluding twin brothers, born between 1955-65.

In total 1,734,056 observations and 45345 sibling pairs. 
Table 2: Descriptive statistics for twin brothers: Means and standard deviations

\begin{tabular}{lcccccc}
\hline \hline & \multicolumn{2}{l}{ fathers-at-some-point } & \multicolumn{2}{c}{ childless men } & \multicolumn{3}{c}{ childless men } \\
& & & & & \multicolumn{2}{c}{ married-at-some-point } \\
& mean & sd. & mean & sd. & mean & sd. \\
\hline log(earnings) & 12.38 & .51 & 12.23 & .52 & 12.35 & .45 \\
real annual earnings (1000 Nkr) & 250.4 & 192.4 & 211.2 & 146.8 & 228.5 & 147.7 \\
yrs of education & 12.11 & 2.48 & 11.70 & 2.50 & 11.12 & 2.18 \\
age & 33.22 & 7.51 & 32.78 & 7.44 & 33.45 & 7.75 \\
age at first marriage & 30.74 & 4.37 & 34.73 & 5.41 & 34.73 & 5.41 \\
age at first birth & 28.47 & 5.39 &. &. &. &. \\
number of children & 2.33 & .98 & 0 & 0 & 0 & 0 \\
year first job & 1980 & 3.57 & 1981 & 3.79 & 1979 & 3.14 \\
yrs of experience & 14.25 & 7.45 & 13.25 & 7.30 & 14.69 & 7.63 \\
yrs of experience before first birth & 2.16 & 4.12 & 13.25 & 7.30 & 14.69 & 7.63 \\
year of birth & 1959 & 3.21 & 1959 & 3.23 & 1958 & 3.02 \\
Year of birth first child & 1988 & 6.54 &. &. &. &. \\
Year of birth second child & 1991 & 6.15 &. &. &. &. \\
married-at-some-point & 0.81 & 0.39 & 0.20 & 0.4 & 1 & \\
number of obs. twin brothers & 36218 & & 8230 & & 1515 & \\
\hline \hline
\end{tabular}

Data: Norwegian register data until 2005. ${ }^{*}$ available since 1986.

Pooled sample of first and second born twin brothers born between 1955-65.

In total 44448 observations and 1069 twin pairs. 


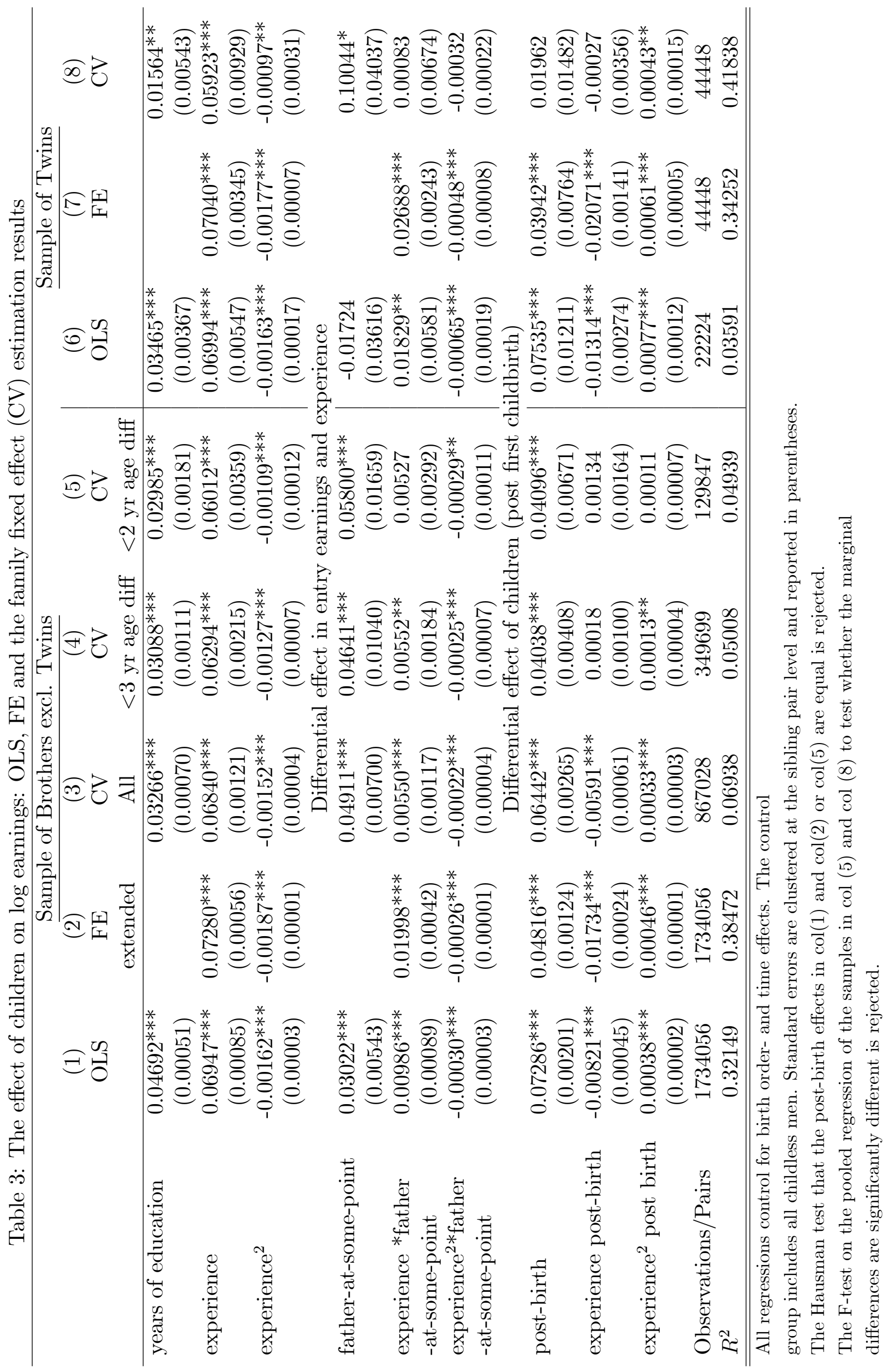




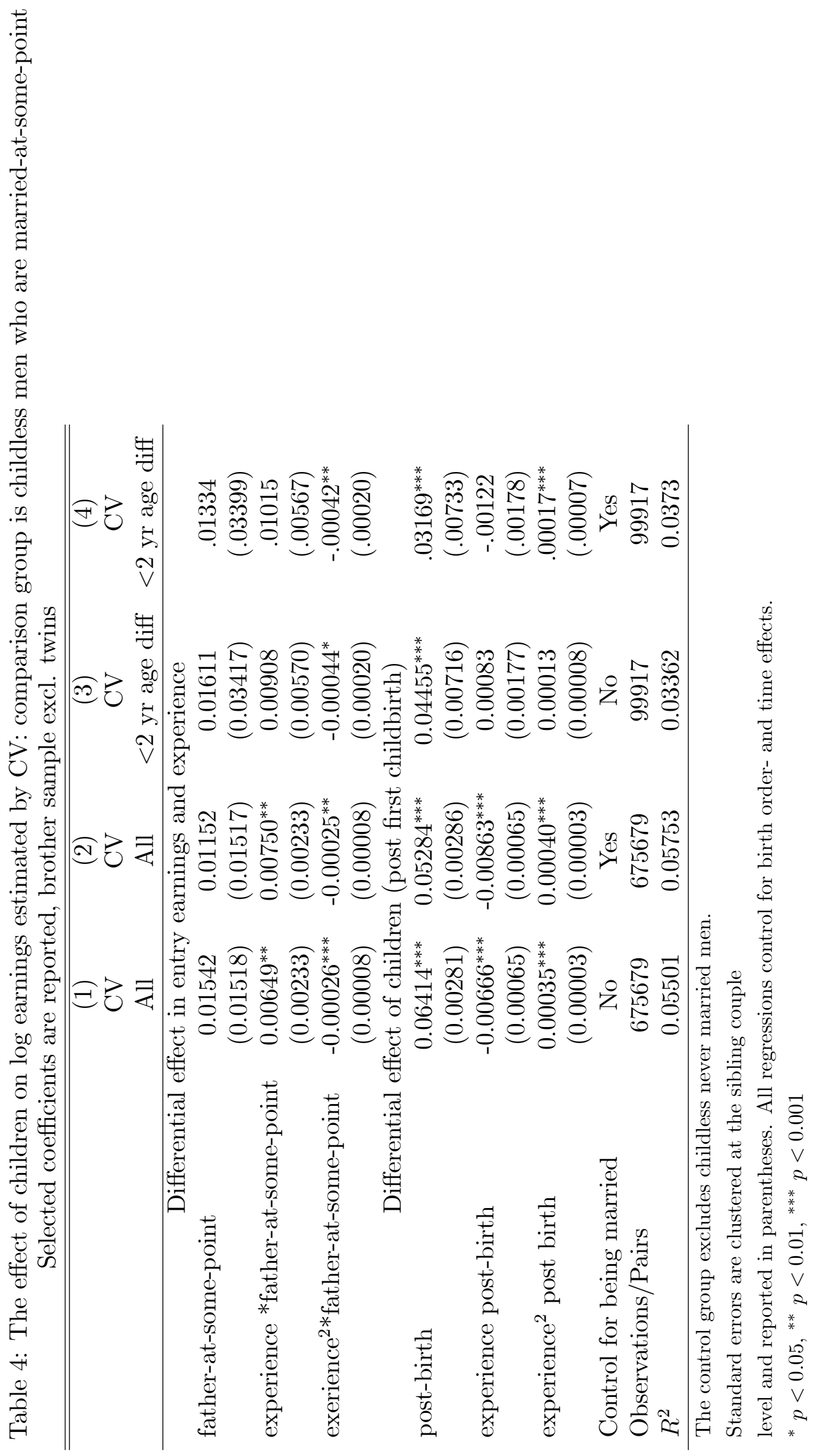


Table 5: Correlations of education and completed fertility between siblings

\begin{tabular}{lccc}
\hline \hline & Years of & $\begin{array}{c}\text { whether children } \\
\text { or not } \\
1 \text { if yes }\end{array}$ & $\begin{array}{c}\text { number of } \\
\text { children }\end{array}$ \\
\hline Brothers, all & $0.3567^{*}$ & $0.1128^{*}$ & $0.1325^{*}$ \\
Number of sibling couples & 45345 & 45345 & 45345 \\
Brothers, $<3$ yrs age difference & $0.3697^{*}$ & $0.1169^{*}$ & $0.1335^{*}$ \\
Number of sibling couples & 18256 & 18256 & 18256 \\
Twins & $.5170^{*}$ & $.2420^{*}$ & $.2402^{*}$ \\
Number of sibling couples & 1069 & 1069 & 1069 \\
2 randomly selected men & .002 & -.009 & -.003 \\
Number of random couples & 20000 & 20000 & 20000 \\
\hline \hline
\end{tabular}

* significant at 5 percent significance level.

Table 6: Descriptive statistics for sibling brothers: Means and standard deviations

\begin{tabular}{llccc}
\hline \hline & \multicolumn{2}{l}{ fathers-at-some-point } & \multicolumn{2}{c}{ childless men } \\
& mean & sd. & mean & sd. \\
\hline $\log$ (earnings) & 12.35 & .525 & 12.22 & .53 \\
yrs of education & 12.16 & 2.5 & 11.91 & 2.64 \\
yrs of experience & 12.50 & 7.01 & 12.15 & 7.0 \\
\hline
\end{tabular}

Only sibling couples with unequal fertility outcome (children yes or no). 
Table 7: Testing compositional effects: Earnings regression results only using brother couples with unequal fertility outcome $(0 / 1)$

\begin{tabular}{|c|c|c|}
\hline & $\begin{array}{c}\text { (1) } \\
\text { OLS }\end{array}$ & $\begin{array}{c}(2) \\
\text { CV } \\
\text { less than } 2 \text { years } \\
\text { age difference }\end{array}$ \\
\hline years of education & $\begin{array}{c}0.044^{* * *} \\
(0.001)\end{array}$ & $\begin{array}{c}0.033^{* * *} \\
(0.001)\end{array}$ \\
\hline experience & $\begin{array}{c}0.074^{* * *} \\
(0.002)\end{array}$ & $\begin{array}{c}0.067^{* * *} \\
(0.003)\end{array}$ \\
\hline experience $^{2}$ & $\begin{array}{c}-0.002^{* * *} \\
(0.000)\end{array}$ & $\begin{array}{c}-0.001^{* * *} \\
(0.000)\end{array}$ \\
\hline \multicolumn{3}{|c|}{ Differential effect in entry earnings and experience } \\
\hline father-at-some-point & $\begin{array}{c}0.038^{* * *} \\
(0.011)\end{array}$ & $\begin{array}{l}0.038^{* *} \\
(0.011)\end{array}$ \\
\hline experience ${ }^{*}$ father-at-some-point & $\begin{array}{c}0.009^{* * *} \\
(0.002)\end{array}$ & $\begin{array}{c}0.009^{* * *} \\
(0.002)\end{array}$ \\
\hline exerience $^{2 *}$ father-at-some-point & $\begin{array}{c}-0.000^{* * *} \\
(0.000)\end{array}$ & $\begin{array}{c}-0.000^{* * *} \\
(0.000)\end{array}$ \\
\hline \multicolumn{3}{|c|}{ Effect of children (post first childbirth) } \\
\hline post-birth & $\begin{array}{c}0.041^{* * *} \\
(0.009)\end{array}$ & $\begin{array}{c}0.012 \\
(0.013)\end{array}$ \\
\hline experience post-birth & $\begin{array}{l}-0.004^{*} \\
(0.002)\end{array}$ & $\begin{array}{c}0.005^{*} \\
(0.002)\end{array}$ \\
\hline experience $^{2}$ post birth & $\begin{array}{c}0.000 \\
(0.000)\end{array}$ & $\begin{array}{l}-0.000 \\
(0.000)\end{array}$ \\
\hline Observations/Pairs & 64364 & 32182 \\
\hline$R^{2}$ & 0.314 & 0.093 \\
\hline
\end{tabular}

All regressions control for birth order- and time effects.

The control group includes all childless men.

Standard errors are clustered at the sibling couple level and reported in parentheses.

${ }^{*} p<0.05,{ }^{* *} p<0.01,{ }^{* * *} p<0.001$ 


\section{Appendix}

Appendix Table A1: Distribution of total number of children of a person, in 2005

\begin{tabular}{lcccc}
\hline \hline \multirow{2}{*}{ Number of children } & \multicolumn{3}{c}{ Birth Cohorts 1955-65 } & \multicolumn{2}{c}{ Birth Cohort 1955 } \\
& All men & Brothers & Twins & National Statistics, men* \\
\hline zero children & 19.46 & 19.03 & 21.78 & 16.6 \\
one child & 13.94 & 13.65 & 14.80 & 13.2 \\
two children & 36.64 & 36.15 & 35.04 & 37.1 \\
three children & 23.37 & 22.96 & 20.57 & 23.3 \\
four or more & 8.14 & 8.21 & 7.82 & 9.9 \\
Total & 100 & 100 & 100 & 100 \\
\hline \hline
\end{tabular}

*Source: Statistics Norway. 
Appendix Table A2: Summary statistics: Variables in differences $=X_{\text {firstborn }}-X_{\text {secondborn }}$

\begin{tabular}{lcccc}
\hline \hline & Brothers & Twin Sample & \\
& mean & sd & mean & sd. \\
\hline$\Delta \log ($ earnings $)$ & .09 & .59 & -.02 & .52 \\
$\Delta$ (father type $)$ & .02 & .51 & -.00 & .50 \\
$\Delta$ yrs of education & .05 & 3.19 & -.04 & 2.75 \\
$\Delta$ yrs of experience & 3.00 & 3.39 & .00 & 2.45 \\
.. experience squared & 84.47 & 113.25 & .37 & 80.61 \\
$\Delta$ yrs of experience*fathertype & 2.74 & 7.90 & -.00 & 7.90 \\
$\ldots$ experience squared*fathertype & 75.22 & 178.42 & -.29 & 176.95 \\
$\Delta$ (post birth) & .12 & .57 & -.01 & .54 \\
$\Delta$ yrs of experience*post-birth & 2.49 & 6.76 & -.23 & 6.14 \\
.. experience squared *post-birth & 48.73 & 138.89 & -4.66 & 125.60 \\
Difference in year of birth & -1.16 & .41 & 0 & \\
Number of observations & 867028 & & 22224 & \\
\hline \hline
\end{tabular}


Appendix Table A3: Earnings regression results, brothers 1 year age difference: Number of children

\begin{tabular}{|c|c|c|c|}
\hline & $\mathrm{CV}$ & $\mathrm{CV}$ & $\mathrm{CV}$ \\
\hline \multirow[t]{2}{*}{ education } & $0.02676^{* * *}$ & $0.02673^{* * *}$ & $0.02295^{* * *}$ \\
\hline & $(0.00210)$ & $(0.00210)$ & $(0.00219)$ \\
\hline \multirow[t]{2}{*}{ experience } & $0.04881^{* * *}$ & $0.04854^{* * *}$ & $0.04511^{* * *}$ \\
\hline & $(0.00619)$ & $(0.00619)$ & $(0.00663)$ \\
\hline \multirow[t]{2}{*}{ experience $^{2}$} & $-0.00083^{* * *}$ & $-0.00081^{* * *}$ & $-0.00065^{* *}$ \\
\hline & $(0.00021)$ & $(0.00021)$ & $(0.00023)$ \\
\hline \multicolumn{4}{|c|}{$\underline{\text { Differential effect in entry earnings and experience }}$} \\
\hline \multicolumn{4}{|l|}{ father type separated into } \\
\hline \multirow[t]{2}{*}{$=1$ child } & -0.02372 & -0.01646 & -0.03061 \\
\hline & $(0.03531)$ & $(0.03532)$ & $(0.03696)$ \\
\hline \multirow[t]{2}{*}{$=2$ children } & 0.02551 & 0.02188 & -0.00061 \\
\hline & $(0.03430)$ & $(0.03430)$ & $(0.03602)$ \\
\hline \multirow[t]{2}{*}{$=3$ children } & 0.02211 & 0.02156 & -0.00022 \\
\hline & $(0.03453)$ & $(0.03453)$ & $(0.03632)$ \\
\hline \multirow[t]{2}{*}{$=4$ children } & 0.01383 & 0.01233 & -0.00399 \\
\hline & $(0.03599)$ & $(0.03603)$ & $(0.03775)$ \\
\hline \multirow[t]{2}{*}{ more than 5 children } & -0.03835 & -0.04191 & -0.06173 \\
\hline & $(0.03904)$ & $(0.03920)$ & $(0.04097)$ \\
\hline \multirow[t]{2}{*}{ experience*father-at-some-point } & 0.01061 & 0.01082 & $0.01641^{* *}$ \\
\hline & $(0.00568)$ & $(0.00568)$ & $(0.00615)$ \\
\hline \multirow[t]{3}{*}{ experience $^{2 *}$ father-at-some-point } & $-0.00043^{*}$ & $-0.00045^{*}$ & $-0.00069^{* *}$ \\
\hline & $(0.00020)$ & $(0.00020)$ & $(0.00022)$ \\
\hline & Effect of having c & ildren & \\
\hline \multirow[t]{2}{*}{ post-birth 1st child } & $0.02982^{* * *}$ & $0.03090^{* * *}$ & $0.03867^{* * *}$ \\
\hline & $(0.00738)$ & $(0.00793)$ & $(0.00970)$ \\
\hline \multirow[t]{2}{*}{ experience post-first birth } & -0.00189 & -0.00213 & -0.00391 \\
\hline & $(0.00180)$ & $(0.00255)$ & $(0.00295)$ \\
\hline \multirow[t]{2}{*}{ experience $^{2}$ post-first birth } & $0.00019^{*}$ & 0.00009 & 0.00015 \\
\hline & $(0.00008)$ & $(0.00012)$ & $(0.00014)$ \\
\hline \multirow[t]{2}{*}{ post-birth 2st child } & & 0.00274 & -0.00042 \\
\hline & & $(0.00753)$ & $(0.00869)$ \\
\hline \multirow[t]{2}{*}{ experience post 2 nd birth } & & 0.00336 & 0.00459 \\
\hline & & $(0.00257)$ & $(0.00292)$ \\
\hline \multirow[t]{2}{*}{ experience squared post 2 nd birth } & & -0.00000 & -0.00001 \\
\hline & & $(0.00015)$ & $(0.00016)$ \\
\hline \multirow[t]{2}{*}{ post-birth 3st child } & & -0.01292 & -0.00871 \\
\hline & & $(0.01017)$ & $(0.01150)$ \\
\hline \multirow[t]{2}{*}{ experience post 3rd birth } & & -0.00308 & -0.00427 \\
\hline & & $(0.00286)$ & $(0.00308)$ \\
\hline \multirow[t]{2}{*}{ experience squared post 3rd birth } & & 0.00034 & $0.00039^{*}$ \\
\hline & & $(0.00017)$ & $(0.00018)$ \\
\hline Observations & 99917 & 99917 & 82747 \\
\hline \multirow[t]{2}{*}{ Comment } & sibling couples & sibling couples & excluding earnings \\
\hline & less than 2 years diff & less than 2 years diff & following a childbirth if after 1993 \\
\hline$R^{2}$ & 0.03929 & 0.03991 & 0.03803 \\
\hline
\end{tabular}

Extended specification of Table 4, column 3, is estimated. For furhter explanations see Table 4. 


\section{Appendix B: Derivation of empirical framework}

This appendix shows how the earnings equation in eq(1) can be derived in a treatment framework as in the study by Heckman and Hotz (1998) that estimated the return to training using non-experimental data. One issue in their application is that those who enter training, the treated, are different before treatment compared to the non-treated, those who do not enter training. This is a similar setting to ours where we want to account for that fathers-at-some-point are on different earnings paths from the beginning of their career in comparison to childless men.

Let $\ln y_{\text {ift }}$ be observed logarithmic earnings of individual $i$ in period $t$, and $\ln y_{i t}^{*}$ the logarithmic earnings in the absence of children. (We add subscript for family $f$ which we return to later.) The indicator variable $a_{i f t}$ equals one if a person becomes a father (treated) and zero otherwise (untreated) and $\gamma_{t}$ is the effect of children in period $t$. We assume that the effect of children is identical for all persons. The period of childbirth is denoted as $\mathrm{k}$. Then we can write:

$$
\begin{array}{r}
\ln y_{i f t}=\ln y_{i f t}^{*}+\gamma_{t} a_{i f t}, \quad a_{i f t}=1, t>k \\
\ln y_{i f t}=\ln y_{i f t}^{*}, \quad a_{i}=0, t<=k
\end{array}
$$

We will focus on estimating the mean effect and the difference in mean post-birth earnings of fathers and non-fathers is:

$$
\begin{array}{r}
E\left[\ln y_{i f t} \mid a_{i f t}=1\right]-E\left[\ln y_{i f t} \mid a_{i f t}=0\right] \\
=E\left[\gamma_{t} \mid a_{i f t}=1\right]+\left\{E\left[\ln y_{i f t}^{*} \mid a_{i f t}=1\right]-E\left[\ln y_{i f t}^{*} \mid a_{i f t}=0\right]\right\}
\end{array}
$$

The expression in parentheses is the selection bias which is present if the assignment to fatherhood is not random. ${ }^{1}$

Suppose $\ln y_{i t}^{*}$ is a linear function of a set of observed characteristics $X_{i t}$ and unobserved characteristics $\epsilon_{i t}$.

$$
\ln y_{\text {ift }}^{*}=X_{i f t} \beta_{1}+\epsilon_{i f t}
$$

\footnotetext{
${ }^{1}$ Since men typically work continuously non-random selection into work is not important and we can neglect this issue. To incorporate women with more disruptive careers would make the estimation approach more complicated.
} 
Then observed earnings may be written as

$$
\ln y_{i f t}=X_{i f t} \beta_{1}+\gamma_{t} a_{i f t}+\epsilon_{i f t}
$$

In the empirical application the vector $X$ contains a constant and standard controls for years of education and experience (squared) counted since entry into the labor market. We assume that $E\left(\epsilon_{i t} X_{i t}\right)=0$ for all $i$ and $t .^{2}$

The decision to become a father can be quite generally written in terms of an index-function framework, where the index, father, is a function of both observed, $\mathrm{Z}$, and unobserved, $\mathrm{u}$, characteristics:

$$
\text { father }_{i f t}=Z_{i f} \alpha+u_{i f t}
$$

Then, the ith individual's fatherhood status is

$$
\begin{aligned}
& a_{i f t}=1 \quad \text { iff } \text { father }_{\text {ift }}>0 \\
& =0 \quad \text { otherwise }
\end{aligned}
$$

We assume $u$ is iid across individuals and distributed independently of $Z_{i}$. This means that the dependence between $\epsilon$ and $a$ can arise because of dependence between $Z$ and $\epsilon$, i.e. selection on observables, or dependence between $\epsilon$ and $u$, selection on unobservables.

Men who become fathers at some point may have invested already previously more into their careers. In this case, omitted variable bias may arise. ${ }^{3}$

To address selection bias on observable characteristics we employ a linear control function estimator. Inserting a linear version of $E(\epsilon \mid X, Z)^{4}$ in equation (4) yields

$$
l n y_{i f t}=C_{i f t} \delta+\gamma_{t} a_{i f t}+\tilde{\epsilon}_{i f t}
$$

where $C_{\text {ift }}$ denotes the vector of all variables included in either $\mathrm{X}$ or the vector of instruments Z, $\tilde{\epsilon}_{i t}=\epsilon_{i t}-E\left(\epsilon \mid a_{i}, C_{i}\right)=\epsilon_{i t}-E\left(\epsilon_{i t} \mid C_{i}\right)$. In our application

\footnotetext{
${ }^{2}$ The effect of children, $\gamma_{t}=\gamma_{t}\left(a, e x_{p o s t}\right)$, is modelled as a function of the indicator variable $a_{i}$ and post-birth work experience, $e x_{p o s t}$, in order to capture the potential non-linear pattern of the effect after the first childbirth.

${ }^{3}$ Clearly, the direction of selection bias can go either way.

${ }^{4}$ We use that $E(\epsilon \mid a, X, Z)=E(\epsilon \mid X, Z)$. In this case controlling for the observed selection variables $(Z)$ solves the (observed) selection bias problem.
} 
$Z$ will include the indicator variable whether the man is a father-at-some point, fathertype, or not. We exploit the fact that in the data we observe earnings even before a man becomes a father, and that we can distinguish fathers-at-some point from childless men. Additionally, we use the indicator interaction with years of experience (squared) since entry, $e x$.

In sum, we write the log earnings equation:

$$
\ln y_{i f t}=\gamma_{t} a_{i f t}+\beta^{\prime} X_{i t}+\delta^{\prime} Z_{i f t}+\nu_{f}+\mu_{i f}+w_{i f t}
$$

where we write the error term $\tilde{\epsilon}_{i f t}=\nu_{f}+\mu_{i f}+w_{i f t}$, and where individuals are indexed by $i$, and family by $f$, and time by $t$.

Reference: Heckman, J.J. and V.J. Hotz (1989): Choosing among alternative non-experimental methods for estimating the impact of social programs: The case of manpower training, Journal of the American Statistical Association, 84(408), 862-874. 


\section{Appendix C}

Appendix Table C1: Time use of men and women per day, 2010

\begin{tabular}{lcc}
\hline \hline & Market Work & Household work \\
\hline Single men, 24-44 yrs old & 8.24 & 2.12 \\
Single women, 24-44 & 8.24 & 2.22 \\
\multicolumn{3}{c}{ Couple without child, 16-44 } \\
Men & 8.58 & 2.38 \\
Women & 8.04 & 2.4 \\
\multicolumn{3}{c}{ Single parent } \\
men & 7.47 & 4.19 \\
women & 7.32 & 4.17 \\
& Couple with child age 0-6 & 4.29 \\
Men & 8.45 & 5.57 \\
Women & 7.29 & \\
\hline \hline Collected from O.F. Vaage (2012): Tidene skifter: Tidsbruk 1971-2010, \\
Statistics Norway, Oslo Kongsvinger. \\
Couples include married and cohabiting couples. \\
Numbers disaggregated by parenthood status are not available before 2010 from this report.
\end{tabular}




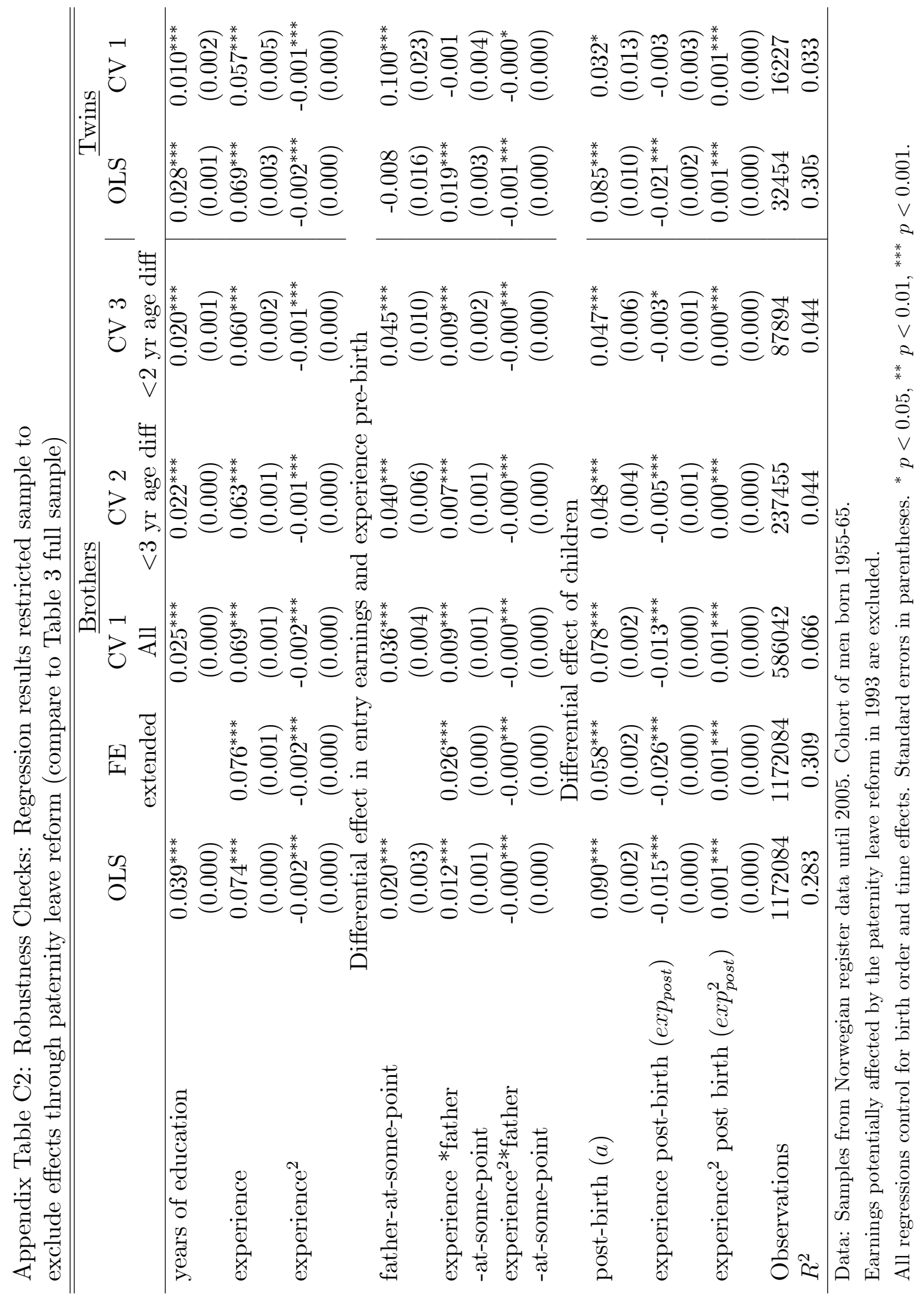


Appendix Table C3: Linear Probability Model results for employment and hours of work

\begin{tabular}{|c|c|c|c|c|}
\hline & \multicolumn{2}{|c|}{$\mathrm{All}^{1}$} & \multicolumn{2}{|c|}{$\overline{\text { Restricted Comparison Group }}^{2}$} \\
\hline & Employment & $\begin{array}{c}\text { More than } \\
30 \text { hours work }\end{array}$ & Employment & $\begin{array}{l}\text { More than } \\
30 \text { hours work }\end{array}$ \\
\hline years of education & $\begin{array}{c}0.018^{* * *} \\
(0.000)\end{array}$ & $\begin{array}{c}-0.003^{* * *} \\
(0.000)\end{array}$ & $\begin{array}{c}0.018^{* * *} \\
(0.000)\end{array}$ & $\begin{array}{c}-0.003^{* * *} \\
(0.000)\end{array}$ \\
\hline experience & $\begin{array}{c}0.021^{* * *} \\
(0.000)\end{array}$ & $\begin{array}{c}0.006^{* * *} \\
(0.000)\end{array}$ & $\begin{array}{c}0.015^{* * *} \\
(0.001)\end{array}$ & $\begin{array}{c}0.005^{* * *} \\
(0.001)\end{array}$ \\
\hline experience $^{2}$ & $\begin{array}{c}-0.000^{* * *} \\
(0.000)\end{array}$ & $\begin{array}{c}-0.000^{* * *} \\
(0.000)\end{array}$ & $\begin{array}{c}-0.000^{* * *} \\
(0.000)\end{array}$ & $\begin{array}{c}-0.000^{* * *} \\
(0.000)\end{array}$ \\
\hline \multicolumn{5}{|c|}{ Differential effect in entry earnings and experience } \\
\hline father-at-some-point & $\begin{array}{c}0.060^{* * *} \\
(0.003)\end{array}$ & $\begin{array}{l}0.004^{*} \\
(0.002)\end{array}$ & $\begin{array}{c}0.014 \\
(0.010)\end{array}$ & $\begin{array}{l}-0.003 \\
(0.005)\end{array}$ \\
\hline experience $*$ father & $-0.003^{* * *}$ & $0.001^{* * *}$ & 0.001 & 0.001 \\
\hline -at-some-point & $(0.001)$ & $(0.000)$ & $(0.001)$ & $(0.001)$ \\
\hline experience $^{2 *}$ father & $0.000^{* * *}$ & $-0.000^{* * *}$ & 0.000 & -0.000 \\
\hline -at-some-point & $(0.000)$ & $(0.000)$ & $(0.000)$ & $(0.000)$ \\
\hline \multicolumn{5}{|c|}{ Differential effect of children (post first childbirth) } \\
\hline post-birth & $\begin{array}{c}0.013^{* * *} \\
(0.001)\end{array}$ & $\begin{array}{c}0.008^{* * *} \\
(0.001)\end{array}$ & $\begin{array}{c}0.002 \\
(0.002)\end{array}$ & $\begin{array}{c}0.004^{* * *} \\
(0.001)\end{array}$ \\
\hline experience post-birth & $\begin{array}{c}-0.003^{* * *} \\
(0.000)\end{array}$ & $\begin{array}{c}-0.001^{* * *} \\
(0.000)\end{array}$ & $\begin{array}{c}-0.004^{* * *} \\
(0.000)\end{array}$ & $\begin{array}{c}-0.001^{* * *} \\
(0.000)\end{array}$ \\
\hline experience $^{2}$ post birth & $\begin{array}{c}0.000^{* * *} \\
(0.000)\end{array}$ & $\begin{array}{l}0.000^{* *} \\
(0.000)\end{array}$ & $\begin{array}{c}0.000^{* * *} \\
(0.000)\end{array}$ & $\begin{array}{c}0.000 \\
(0.000)\end{array}$ \\
\hline Observations & 1655259 & 1655259 & 697224 & 697224 \\
\hline$R^{2}$ & 0.021 & 0.007 & 0.025 & 0.005 \\
\hline
\end{tabular}

All regressions control for birth order and time effects.

${ }^{1}$ All means all fathers-at-some-point and all childless men.

${ }^{2}$ Restricted Comparison Group uses only childless men married at some point as comparison group.

Standard errors in parentheses. ${ }^{*} p<0.05,{ }^{* *} p<0.01,{ }^{* * *} p<0.001$ 